\title{
Improvement of the detection of desert dust over the Sahel using METEOSAT IR imagery
}

\author{
G. Vergé-Dépré ${ }^{1}$, M. Legrand ${ }^{1}$, C. Moulin ${ }^{2}$, A. Alias $^{3}$, and P. François ${ }^{1}$ \\ ${ }^{1}$ Laboratoire d'Optique Atmosphérique, CNRS-USTL, Villeneuve d'Ascq, France \\ ${ }^{2}$ LSCE/IPSL, CEA-CNRS-UVSQ, Gif-sur-Yvette, France \\ ${ }^{3}$ Météo France CNRM/GMGEC-EAC, Toulouse, France
}

Received: 11 April 2006 - Revised: 22 June 2006 - Accepted: 27 June 2006 - Published: 13 September 2006

\begin{abstract}
Desert dust over the arid regions of Africa is detected using the Infrared Difference Dust Index (IDDI) derived from the thermal infrared (TIR) channel of METEOSAT. However, the comparison with photometric aerosol optical thickness (AOT) of this dust index reveals some discrepancies. Using an instrumented site in Sahel where aerosol properties and meteorological conditions were monitored daily during the dry season, we performed radiative transfer computations with the MODTRAN 4.1 code to develop a method to improve the IDDI usefulness. We found that discrepancies between AOT and IDDI variations mostly come from changes in the surface temperature $\left(T_{S}\right)$, which is an important parameter for radiative transfer computations in the TIR. We show that this temperature varies from day to day with the surface wind speed and during the course of the season with the solar elevation, and that it is possible, for the site considered, to correct $T_{s}$ from these combined effect using a simple parameterization. We also observe that the dust layer itself has an impact on $T_{S}$ by reducing the amount of solar radiation at the surface, and that this phenomenon can also be accounted for by adding an AOT-dependence to the above parameterization of $T_{s}$. We show that this parameterization allows improving the agreement between the IDDI and the photometric AOT.
\end{abstract}

Keywords. Atmospheric composition and structure (Aerosols and particles; Geochemical cycles) - Meteorology and atmospheric dynamics (Radiative processes)

\section{Introduction}

Mineral aerosols emitted from deserts and arid regions, are those with the most poorly characterized and most variable optical properties, among the aerosol constituents of

Correspondence to: $\mathrm{M}$. Legrand

(michel.legrand@univ-lille1.fr) the Earth's atmosphere (Liao and Seinfeld, 1998). The Sahara and its borders constitute the main source of mineral dust, yielding over $50 \%$ of the global production. The Saharan dust transport is a significant climatic process (Tanré and Legrand, 1991), primarily westwards, across the Atlantic Ocean (D'Almeida, 1986; Prospero and Lamb, 2003; Petit et al., 2005), but also northwards (Moulin et al., 1998). Mineral dust absorbs and scatters the shortwave and longwave radiations, as well as it emits longwave radiation. Its efficiency over such a broad spectrum arises from the broad size spectrum of dust particles ( 0.1 to $10 \mu \mathrm{m}$ and even larger) (Tanré et al., 2001). Its radiative impact is significant, due to the large atmospheric loading in the regions of generation and transport and because the minerals involved are absorbing in spectral bands, resulting in significant radiative effects in both the shortwave (UV, visible) and the longwave (TIR). In light of these general features, the radiative forcing of mineral aerosol at regional and global scales is considered significant, but it is badly known (Seinfeld et al., 2004). Microphysical and optical characteristics of mineral dust have been studied through measurements, e.g. using the photometer network AERONET (Tanré et al., 2001) as well as through theory (Sokolik et al., 1998), especially in the TIR. From space, the presence of mineral dust over continents in arid regions is detected in the UV and in the TIR. Herman et al. (1997) used the Total Ozone Mapping Spectrometer Absorbing Aerosol Index (TOMS AAI) in the UV. Legrand et al. (2001) computed the Infrared Difference Dust Index (IDDI) in the TIR, using the IR channel of METEOSAT. Recently, Pierangelo (2005) used TIROS Operational Vertical Sounder (TOVS) data in the TIR to detect mineral dust. Recent methods have been proposed using the visible, which is a favorable feature for a comparison with photometric measurements. This is the case of the aerosol optical thickness (AOT) retrieved from MISR (Kahn et al., 2005) and of the measurements in the blue part of the visible spectrum from MODIS (Hsu et al., 2004). 


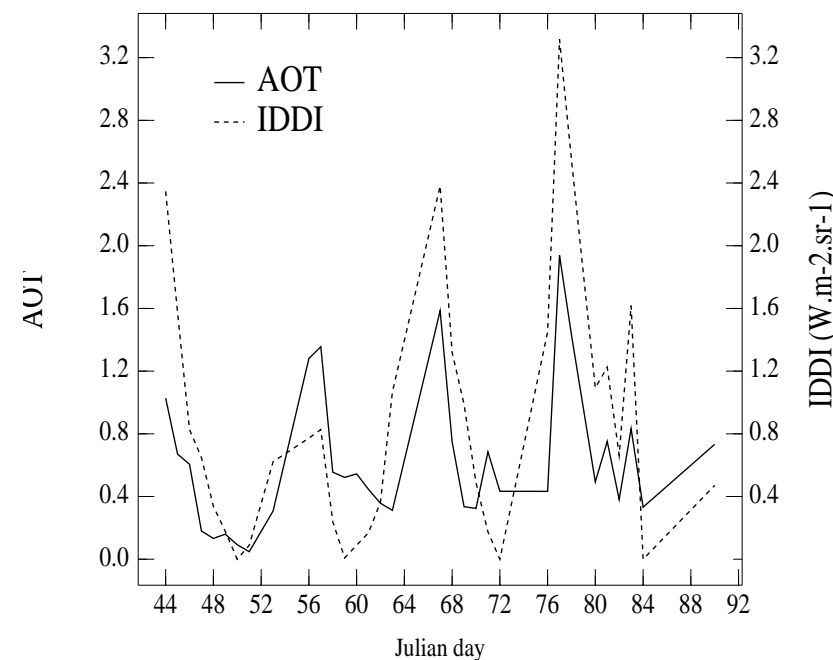

Fig. 1. Temporal evolutions of the IDDI and the AOT from 13 February to 31 March 1998, Banizoumbou.

The IDDI has been employed to the study of various applications including dust climatology (Brooks and Legrand, 2000), sources (Léon and Legrand, 2003), transport (Petit et al., 2005), composition (Caquineau et al., 2002); to validation of dust emission modeling (Marticorena et al., 1997) and of satellite desert surface mapping (Marticorena et al., 2004). Because the AOT is the most popular measure of the aerosol amount, the IDDI index is compared to it. Examples of close correlation between IDDI and photometric AOT can be found (Legrand et al., 2001), but this is not systematic and cases with discrepancies and poor correlation can be found as well. Such an example is studied in Tanré and Legrand (1991) for measurements near Dakar, along the Atlantic coast of Africa. In this case, the impact of water vapor has to be considered, in order that a corrected IDDI, closely correlated with photometric AOT, can be derived. Other sources of error related to the algorithm has been described and estimated in Legrand et al. (2001). The IDDI algorithm creates a reference image, ideally dust-free, but indeed biased with residual amounts of dust. Another error is involved on the reference image by the seasonal changes (chiefly the modulation of the solar irradiance). In this paper, the uncertainties involved on the IDDI signal by various non dust factors are carefully put in evidence and analyzed for the case of the Sahelian station of Banizoumbou, near Niamey, during the dry season of 1998. A method to compute a corrected IDDI is proposed and is evaluated through the improved agreement between IDDI and photometrically measured AOT. A purpose of this work is to improve the IDDI for climate applications, so as to exploit the METEOSAT archive starting in 1982. Such results are also relevant inasmuch as remote sensing in the TIR is concerned (e.g. with the new MSG/SEVIRI). In Sect. 2, we compare IDDI and AOT at Banizoumbou, in February-March 1998. The satellite-measured radiance re-

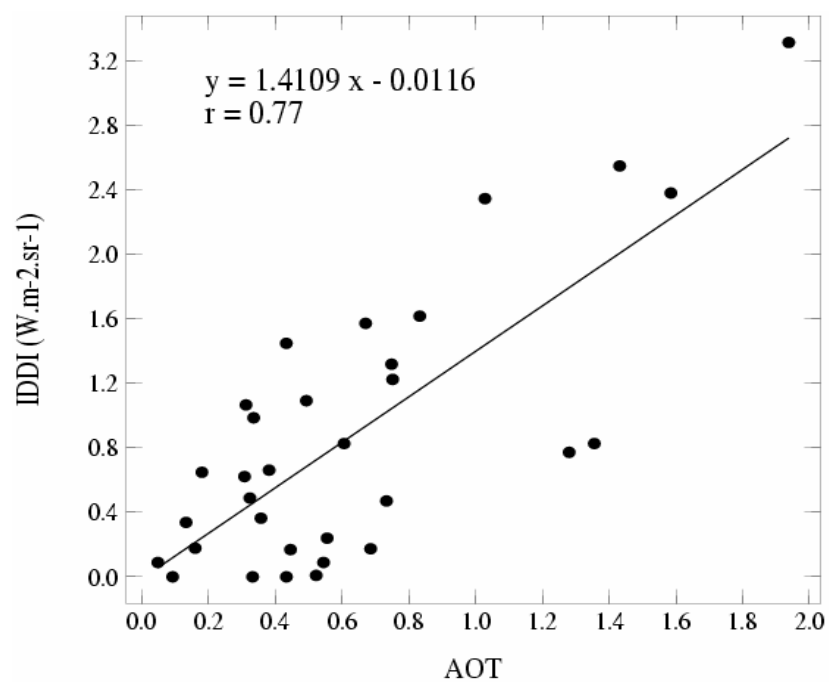

Fig. 2. Comparison between the IDDI and the AOT with data from 13 February to 31 March 1998, Banizoumbou.

sults from the combined effects of the atmosphere and the surface. These physical principles are described and analyzed using a radiative transfer code, as described in Sect. 3. Section 4 is dedicated to the calculated impacts of dust and non dust factors onto the surface temperature. A quantitative sensitivity of the surface to disturbing elements will be established. Finally, in Sect. 5, the upward TIR radiance at the TOA is corrected from the non dust effects and the impact on the METEOSAT IDDI is presented.

\section{Comparison of METEOSAT IDDI with in situ AOT}

The AOT was measured at $1020,870,670$ and $440 \mathrm{~nm}$ during the NIGER-98 campaign with a CIMEL portable Sunphotometer. The field experiment NIGER-98 was carried out from February to May 1998 at the Sahelian site of Banizoumbou $\left(13^{\circ} 32^{\prime} \mathrm{N}, 2^{\circ} 39^{\prime} \mathrm{E}\right)$ in the Republic of Niger, at $50 \mathrm{~km}$ from Niamey. Over the period used for the study, covering February and March 1998, the AOT values at $670 \mathrm{~nm}$ varied between 0.05 and 1.94, as shown in Fig. 1.

The satellite METEOSAT-6 was in operation up to May 1998 (http://www.eumetsat.int). It measured at half-hour intervals, TOA radiances in the IR channel [10.5-12.5 $\mu \mathrm{m}]$. The radiances from the site of Banizoumbou at 12:00 UTC have been used jointly with the photometric data simultaneously measured. They vary over the studied period between 13.95 and $17.44 \mathrm{~W} \cdot \mathrm{m}^{-2} \cdot \mathrm{sr}^{-1}$. The Infrared Difference Dust Index (IDDI), defined in Legrand et al. (2001), is computed as the difference for cloud-free pixels between the satellite radiance of a midday METEOSAT IR [10.5-12.5 $\mu \mathrm{m}] \mathrm{im}$ age and the maximum radiance measured over a running reference period of 15 days. Ideally, this reference image is composed only of cloud-free and dust-free pixels. Clouds 
and dust are assumed to be the only factors impacting on the TOA radiance. The obtained IDDI values vary between 0 and $3.32 \mathrm{~W} . \mathrm{m}^{-2} \cdot \mathrm{sr}^{-1}$ over the period used for the study, as shown in Fig. 1.

The IDDI is a measure of the radiative impact of dust at the TOA in the range [10.5-12.5 $\mu \mathrm{m}]$. A strong correlation of the IDDI with the AOT is thus expected. The temporal evolutions of IDDI and AOT are compared in Fig. 1. Coincident peaks of both parameters are observed on Julian days 44, 67 and 77 (13 February and 8 and 18 March corresponding to strong dust events with AOT larger than 1. However, there are also discrepancies, especially for the period from the (Julian) day 53 to 62 (corresponding to 22 February and 3 March).

Figure 2 compares IDDI values to the measured AOT at $670 \mathrm{~nm}$. With a correlation coefficient of 0.77 , this figure shows a significant scatter of the points around the regression line characterized with a standard deviation of $0.85 \mathrm{~W} . \mathrm{m}^{-2} \cdot \mathrm{sr}^{-1}$.

In order to explain these discrepancies and potentially to improve the IDDI, we will analyze in the following the physics of the radiative transfer in presence of dust, and especially the role of the ground surface temperature, using the available data.

\section{Radiative impact of dust on METEOSAT measure- ments}

\subsection{The MODTRAN-4.1 radiative transfer model}

The MODTRAN-4.1 (Moderate Resolution Transmittance code) is a radiative transfer code (Anderson et al., 1995) dedicated to the computation of atmospheric transmittances and radiance. We use it to calculate the TOA radiance, particularly in the presence of aerosols. The filtering function of METEOSAT-6 IR channel has been introduced in the program for radiance computation. In addition to photometric data, vertical atmospheric profiles from balloon soundings, ground surface emissivity and temperature have been used to model the TOA radiance.

The desert aerosol used in our calculations is modeled using the measurements realized in the region of Niamey (Sahel) (Pancrati, 2003). The vertical distribution of the aerosol is derived from the soundings performed at $\mathrm{Ni}$ amey airport. The top of the dust layer is obtained using the potential temperature profiles and the water vapor density profiles (Ben Mohamed and Frangi, 1986). The dust layer is always at the contact of the surface and its thickness varies from 0.8 to $5 \mathrm{~km}$ during the studied period (13 February to 31 March 1998). The particle size distribution is derived from the AERONET retrieval (Dubovik et al., 2002a) from the photometric measurements of the station of Banizoumbou (PI D. Tanré) $50 \mathrm{~km}$ of Niamey. It is dominated by large particles with a modal radius at $2 \mu \mathrm{m}$.
The dust particles are supposed to be spheroids and the real part of the retrieved refractive index is 1.4 (Dubovik et al., 2002b). This Sahelian aerosol is known to be a mixture of clay and quartz particles. Relative percentages in mass for kaolinite, illite and quartz are respectively 71.6, 9.1 and 19.3, as derived from measurements performed at Banizoumbou (Caquineau, 1997). The ratio between relative abundance of illite and kaolinite is 0.1 which is typical to Sahelian regions (Caquineau et al., 2002).

The balloon soundings performed daily at Niamey airport (50 km from Banizoumbou) at 12:00 UTC measure atmospheric pressure, temperature and humidity profiles. Some days were missing and some soundings were incomplete. Then we used the atmospheric soundings from the University of Wyoming archive (http://weather.uwyo.edu/upperair/ sounding.html to complete our data base.

Surface wind speed measurements at $10 \mathrm{~m}$ performed at the Niamey airport have been provided by the European Centre for Medium-Range Weather Forecasts (ECMWF), from their archive: (http://www.ecmwf.int/). The values are in the range 1.67 to $9.0 \mathrm{~m} . \mathrm{s}^{-1}$ over the studied period. The ground surface emissivity for the spectral range [10.5$12.5 \mu \mathrm{m}$ ] of METEOSAT IR is set to 0.982 , (LARC, NASA: http://snowdog.larc.nasa.gov/surf/pages/emiss.html).

In this study, the ground surface temperature was neither measured nor imposed. It is actually unknown but fitted so as to simulate the METEOSAT signal for the site of Banizoumbou.

\subsection{Radiance outgoing to space and surface temperature}

The presence of a dust layer over land involves a radiative impact at the surface which modifies the surface temperature (Legrand et al., 2001). During the day time, the solar flux incident to the dust layer is partly backscattered to space and partly transmitted through this layer. The reduction of the incident solar flux involves a cooling of the surface. Hence, the surface emits a reduced TIR radiation. This radiation is then attenuated during its transfer through the dust layer before reaching space.

In consequence, the radiance measured by the satellite will be reduced in presence of dust, as the result of two additive effects (Fig. 3): (1) a solar flux reduction involving a decrease of the surface temperature and hence a decrease of surface radiative emission, (2) an attenuation of the TIR upward radiation during its transfer through the dust layer.

Thus, a dust layer has a radiative effect on the ground surface temperature as well as on the TIR radiance outgoing to space. Taking into account these two mechanisms in our simulations is essential. Whereas the MODTRAN-4.1 computes explicitly the attenuation of the TIR radiation by the dust layer, neither the ground surface temperature nor its variation due to dust presence can be calculated directly with the code. This temperature is indeed an input parameter to the 


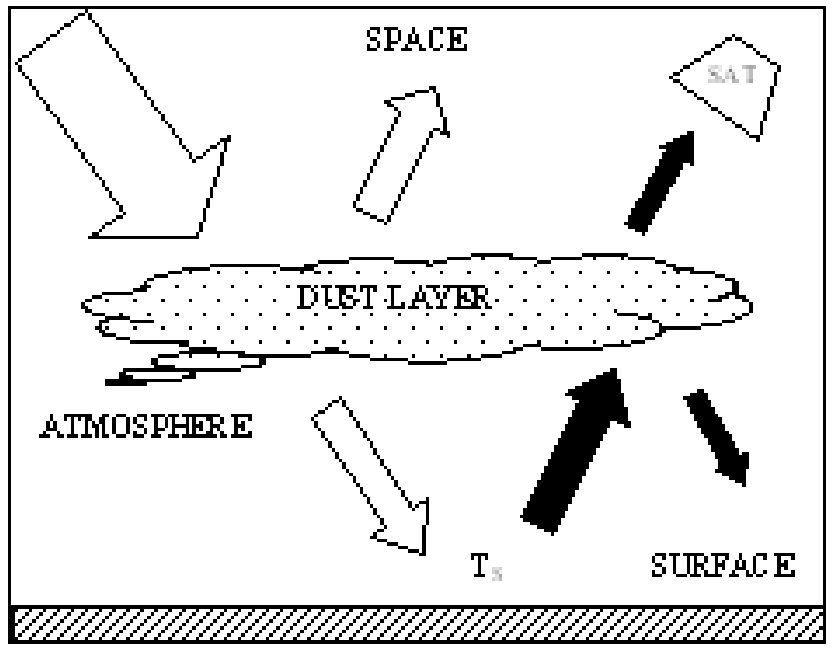

Fig. 3. Radiative impact of a dust layer on ground surface temperature and on the TIR radiance outgoing to space. The black arrows are the TIR radiances and the white ones are the solar fluxes.



Fig. 4. Retrieved surface temperature versus AOT at 12:00 UTC from 13 February to 31 March 1998, at Banizoumbou.

code and we thus have to estimate its value in the presence of dust.

Finally, the importance of $T_{s}$ for the radiative transfer in the TIR raises the problem of the variations of $T_{S}$ with environmental conditions other than a dust layer. It is for example likely that $T_{S}$ varies with the surface wind speed, which modifies the sensible heat flux, and with the solar elevation, which directly controls the incoming solar flux. In the following section, we quantify the respective impacts of these various processes on the TIR radiance at TOA.

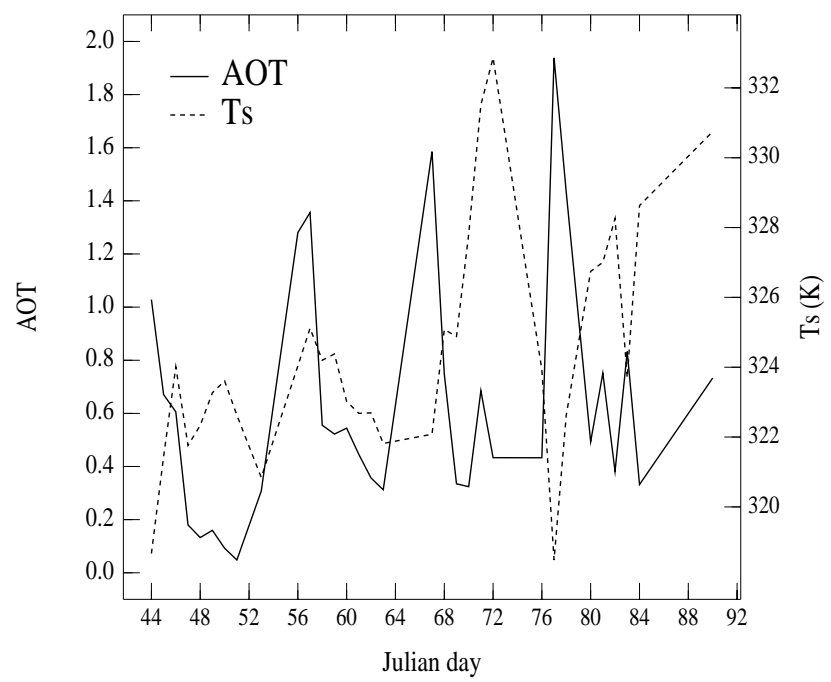

Fig. 5. Temporal series of the retrieved surface temperature and the AOT at 12:00 UTC from 13 February to 31 March 1998, at Banizoumbou.

\section{Variability of the surface temperature}

\subsection{Effect of dust}

We set up an iterative scheme so as to compute the ground surface temperature using the radiative transfer code MODTRAN-4.1, the METEOSAT-6 data, the atmospheric profiles, the AOT and the surface emissivity. In this calculation, the ground surface temperature is varied until the computed TOA radiance is equal to the measured one.

In order to estimate the dust radiative impact on ground surface temperature $\left(T_{s}\right)$, we plot it against the AOT and the least square regression line is drawn (Fig. 4). The slope of the regression line is negative, in agreement with the previous physical description. In addition, we compared the temporal evolutions of the retrieved surface temperature and the AOT (Fig. 5). The two parameters have opposite variations: peaks of AOT (peaks of dust) correspond generally to minimums of retrieved surface temperature. However, on the period from day 53 to 62, already pointed out due to the poor agreement between IDDI and AOT (Fig. 1), $T_{s}$ and AOT do not show opposite variations. This result is related to the low value of the correlation coefficient observed between $T_{s}$ and the AOT $(-0.22)$, indicating that "non-dust" processes (i.e., not due to the radiative impact of dust) are involved in the variability of the surface temperature, contaminating then the IDDI signal. So, in the following we will seek for new disturbing elements and quantify their effect. 


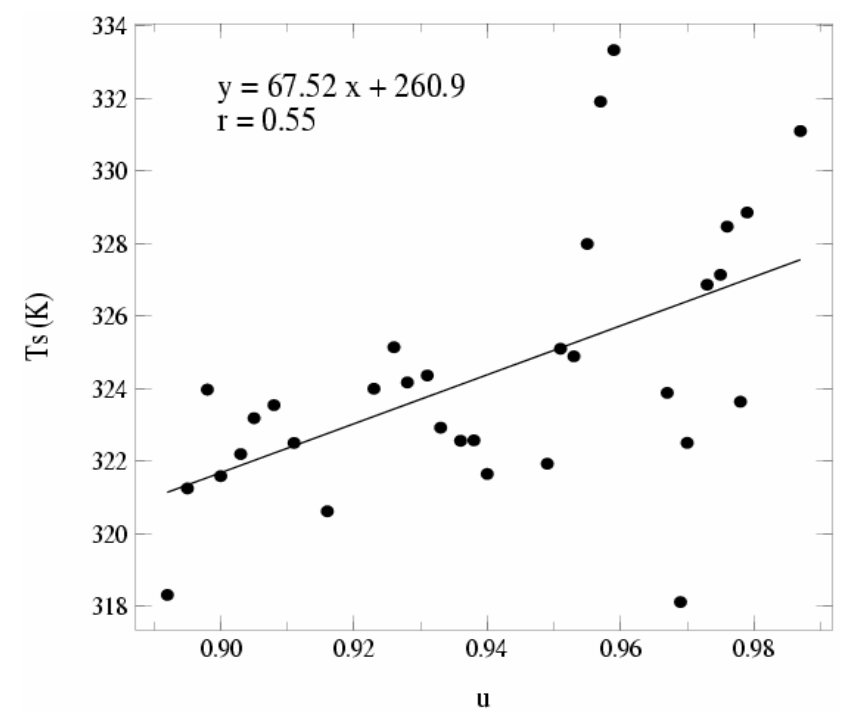

Fig. 6. Retrieved surface temperature versus $\mu$ (cosine of the solar zenith angle) at 12:00 UTC from 13 February to 31 March 1998, Banizoumbou.

\subsection{Non dust effects}

\section{Solar elevation}

February and March, at Banizoumbou, corresponds to the dry season. During this period, the solar height increases and the incident solar irradiance at Earth's TOA is rising as the cosine of the solar zenith angle $\theta_{s}$. This phenomenon involves a seasonal increase of the temperature. In order to estimate this effect, we plot the ground surface temperature versus the cosine $\mu$ of the solar zenith angle $\left(\theta_{s}\right)$ and the least square regression line. Figure 6 shows a correlation coefficient of 0.55 .

\section{Surface wind speed}

During the dry season in Sahelian regions, when the wind blows close to the surface, it drives the transfer of sensible heat between the ground surface and the atmosphere. During daylight, when the surface is overheated, the wind-driven convective transfer of sensible heat results in a cooling of the ground surface. Thus, the surface wind could be a potential source of error for the IDDI signal (Legrand et al., 1992). In Fig. 7, $T_{s}$ is plotted against the measured surface wind speed at $10 \mathrm{~m}\left(V_{s}\right)$. The correlation coefficient obtained between $T_{s}$ and $V_{s}$ is-0.61. Therefore, it is important to include the parameter $V_{s}$ in our simulations.

\section{Atmospheric water vapor}

A priori, the atmospheric water vapor needs to be taken into account for the assessment of the radiance outgoing to space (Tanré and Legrand, 1991). Similarly to dust, the atmospheric water vapor (1) modifies the radiative fluxes, involving a change of the ground surface temperature and of

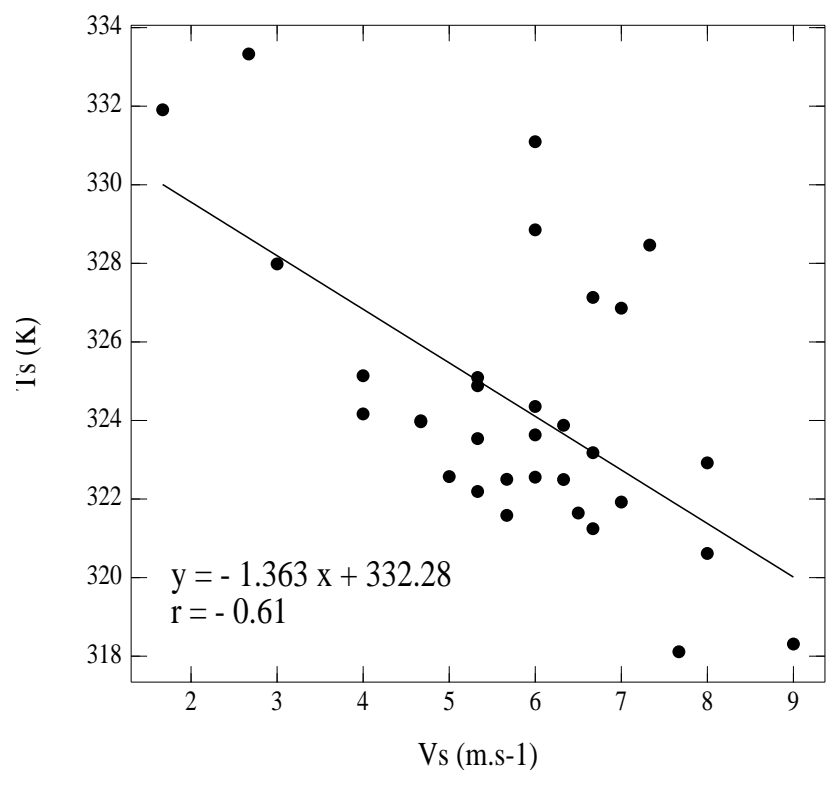

Fig. 7. Retrieved surface temperature versus the measured surface wind speed at $10 \mathrm{~m}$ from 13 February to 31 March 1998, Banizoumbou.

the radiative emission, and (2) modifies the radiative transfer to space by absorbing the surface-emitted radiation and emitting its own radiative component (Legrand et al., 2001). Thus, a change in atmospheric water vapor amount must involve changes in the TOA radiance as well as in the ground surface temperature. However, for Sahelian sites inland, in the dry season (Niamey, Gao), this effect of water vapor has been observed to be negligible (Legrand et al., 2001). In agreement with these observations, the correlation coefficient obtained between the ground surface temperature and the columnar water vapor amount $(-0.07)$ is not significant. Hence, water vapor will not be considered in the following.

\subsection{Parameterization of $T_{s}$}

In conclusion, we have identified three physical factors significantly disturbing the ground surface temperature: the dust amount, the solar elevation and the surface wind speed. To assess the effect of each element on the retrieved surface temperature, we calculate a multiple linear regression against the cosine $\mu$ of the solar zenith angle, the measured surface wind speed $V_{s}$ and the dust optical thickness $\delta_{a}$, using the following parameterization for $T_{s}$ :

$T_{s}\left(\mu, V_{s}, \delta_{a}\right)=a \cdot(\mu-\bar{\mu})+b \cdot\left(V_{s}-\overline{V_{s}}\right)+c \cdot \delta_{a}+T_{s}^{0}$,

where $a, b$ and $c$ are respectively the sensitivities of $T_{s}$ to the solar elevation, to the surface wind and to dust, $\bar{\mu}$ and $\overline{V_{s}}$ are respectively the mean values of $\mu$ and $V_{s}$ over the studied period; $T_{s}^{0}=325.87 \mathrm{~K}$ is the surface temperature for: $\mu=\bar{\mu}, V_{s}=\overline{V_{s}}$ and $\delta_{a}=0$. The multiple correlation coefficient is 0.84 . Table 1 summarizes the values of the coefficients 
Table 1. Summary of the values of a, b, c in Eq. (1) and the partial correlation coefficients (r) between the retrieved surface temperature and the disturbing elements.

\begin{tabular}{llll}
\hline Parameters & $\mu$ & $V_{s}$ & $\delta_{a}$ \\
\hline $\mathrm{r}$ & 0.72 & -0.69 & -0.48 \\
\hline$T_{s}$ & $\mathrm{a}=71.88 \mathrm{~K}$ & $\mathrm{~b}=-1.17 \mathrm{~K} . \mathrm{m}^{-1} . \mathrm{s}$ & $\mathrm{c}=-2.37 \mathrm{~K}$ \\
\hline
\end{tabular}

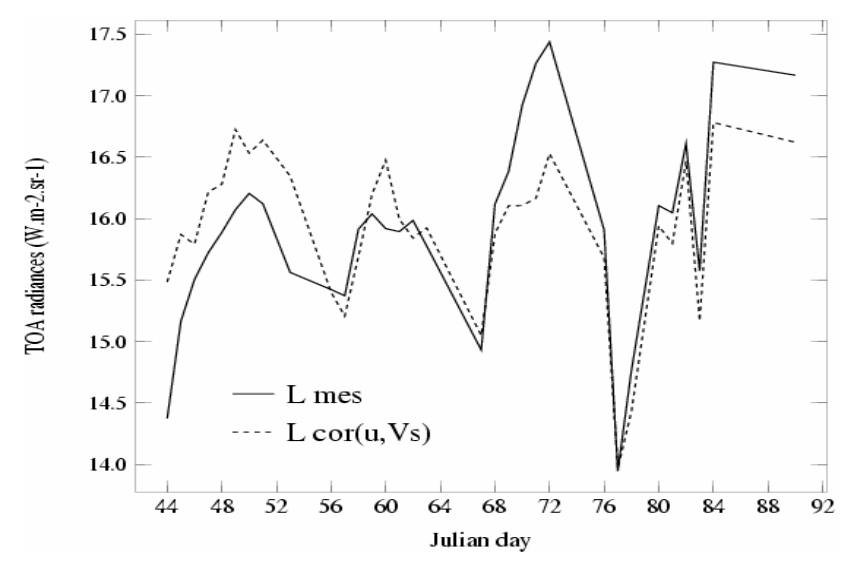

Fig. 8. Temporal series of the satellite radiances $\left(L_{m e s}\right)$ and the corrected TOA radiances $\left(L_{c o r}\left(\mu, V_{s}\right)\right)$ from 13 February to 31 March 1998, Banizoumbou.

$a, b, c$ and the partial correlation coefficients calculated between the retrieved surface temperature $T_{s}$ and the disturbing elements $\left(\mu, V_{s}, \delta_{a}\right)$.

\section{Application to the radiances and the IDDI}

\subsection{Correction of the TOA radiances}

In order to assess the impact of dust at the TOA, radiances outgoing to space are simulated with the MODTRAN code. For this, surface temperatures have been corrected from the solar elevation and surface wind effects using the mean values of $\mu$ and $V_{s}$ in Eq. (1) so as to obtain $T_{s}\left(\bar{\mu}, \overline{V_{s}}, \delta_{a}\right)$. Then, corrected TOA radiances have been calculated introducing these corrected surface temperatures and the actual AOT into the MODTRAN code. Significant differences ranging from -1.10 to $+1.11 \mathrm{~W} \cdot \mathrm{m}^{-2} \cdot \mathrm{sr}^{-1}$ are observed between simulated and the measured radiances (Fig. 8). In addition, the correlation coefficient of 0.63 obtained between the measured radiances $\left(L_{m e s}\right)$ and the AOT rises up to 0.86 using the corrected TOA radiances $\left(L_{c o r}\left(\mu, V_{s}\right)\right)$. These two results are very promising for an application of these corrections to the METEOSAT IDDI at Banizoumbou. Thus a corrected IDDI could be calculated using these corrected radiances.

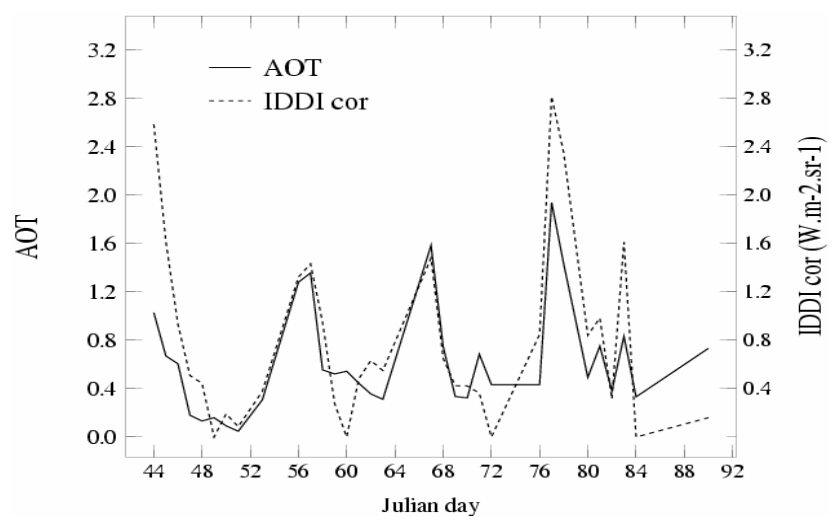

Fig. 9. Temporal series of the AOT and the IDDI corrected from the surface wind speed and the solar elevation effects from 13 February to 31 March 1998, Banizoumbou.

\subsection{Impact on the METEOSAT IDDI}

Before envisaging the development of an inversion method, it is necessary to see whether the parameterization of $T_{s}$ can be used to improve the accuracy of the IDDI by simply correcting the measured radiances from the effect of the surface wind speed and of the solar elevation on $T_{s}$.

The corrected TOA radiances have been calculated introducing these corrected surface temperatures into the MODTRAN code. Then, the corrected IDDI has been computed from these corrected radiances using the same method as the former IDDI. This corrected IDDI varies from 0 to $2.8 \mathrm{~W} \cdot \mathrm{m}^{-2} \cdot \mathrm{sr}^{-1}$ as shown in Fig. 9 and the difference with the former IDDI varies from -0.9 to $+0.7 \mathrm{~W} \cdot \mathrm{m}^{-2} \cdot \mathrm{sr}^{-1}$.

Figure 9 compares the temporal series of the AOT and the corrected IDDI. Figure 10 shows the least square regression and correlation coefficients obtained. The coincidence between the AOT and the corrected IDDI is improved particularly from Julian days 52 to 70 . The scatter of the points around the regression line decreases, the standard deviation is $0.75 \mathrm{~W} . \mathrm{m}^{-2} . \mathrm{sr}^{-1}$ and the correlation coefficient rises to 0.81 . Therefore, taking into account the physical mechanisms at the surface, by correcting the ground surface temperature from surface wind and solar elevation effects, reduces the scatter and improves the correlation between the AOT and the IDDI (derived from the TOA radiances).

We can observe in Fig. 1 that the IDDI dropped down to zero for three days (59, 72 and 84) whereas the AOT values during the running 15-day reference period ( 7 days before and 7 days after the considered day) never decrease below 0.3 . This simply means that the reference image is not completely dust-free and cloud-free (Legrand et al., 2001). Figure 9 shows again these discrepancies, even though the IDDI has been corrected from surface wind speed and solar elevation effects. These persistent shortcomings arise from the differential principle of construction of the reference image 
of the IDDI. Our corrections will not be able to modify that result. Another discrepancy which appears in Fig. 9 is the fact that the peaks of IDDI are not in a constant ratio with the coinciding peaks of AOT. It is possible that this effect arises from change in the radiative and physical properties of the successive events of mineral dust, such as their particle size or composition (Legrand et al., 2001).

\section{Conclusions}

The Infrared Difference Dust Index is the clear-sky TOA radiance in the range [10.5-12.5 $\mu \mathrm{m}]$ derived from the METEOSAT IR images of the middle of the day for estimating the amount of desert dust over continental surfaces. However, the comparison between IDDI and photometric AOT at $670 \mathrm{~nm}$ measured from the ground level at a Sahelian site in the region of Niamey during the dry season of 1998, reveals some discrepancies. Measurements performed in this region during the same period are used to analyse physically the relation between IDDI and photometric AOT. As described in Sect. 3.2, the clear-sky TOA radiance decrease is due to (1) a decrease of the ground surface temperature and (2) a decrease of the TIR upward radiance due to the radiative transfer through the dust layer. The retrieval of the surface temperature using the radiative transfer code MODTRAN 4.1 permits to evaluate the compared importance of the previous processes 1 and 2 . The TOA radiance without dust impact is calculated using the code with a retrieved surface temperature corrected from the dust effect, and a dustfree atmosphere. A TOA radiance with the partial dust impact on surface temperature (process 1) is calculated using the code with the dusty atmosphere and a corrected surface temperature. As a result, we find the day-to-day steady fractions $26 \%$ and $74 \%$ for the surface temperature effect (process 1 ) and for the radiative transfer effect (process 2), respectively. So, the dust impact on the surface temperature is significant at the TOA, and this result suggests that, most generally, the changes of surface temperature must impact significantly the TOA radiance, whatever their physical origin, explaining partly the observed discrepancies observed between IDDI and AOT. So the previous study focuses on the non-dust impacts on ground surface temperature $T_{s}$. A least square linear regression of $T_{s}$ upon $\delta_{a}$ provides a negative slope of the regression line $(-1.7 \mathrm{~K})$. Peaks of dust generally correspond to minimums of $T_{s}$, however the correlation coefficient is only -0.22 , showing that the AOT cannot explain all the variations of $T_{S}$. Further investigations have shown that (i) the seasonal increase of solar irradiance at this period of the year (13 February to $31 \mathrm{March}$ ) in the region of Niamey and (ii) the surface wind and its impact on the sensible heat transfer from superficial ground to atmosphere, could explain to a large extent the surface temperature variations not due to dust. On the other hand, the expected effect of atmospheric water vapor on ground surface temperature is

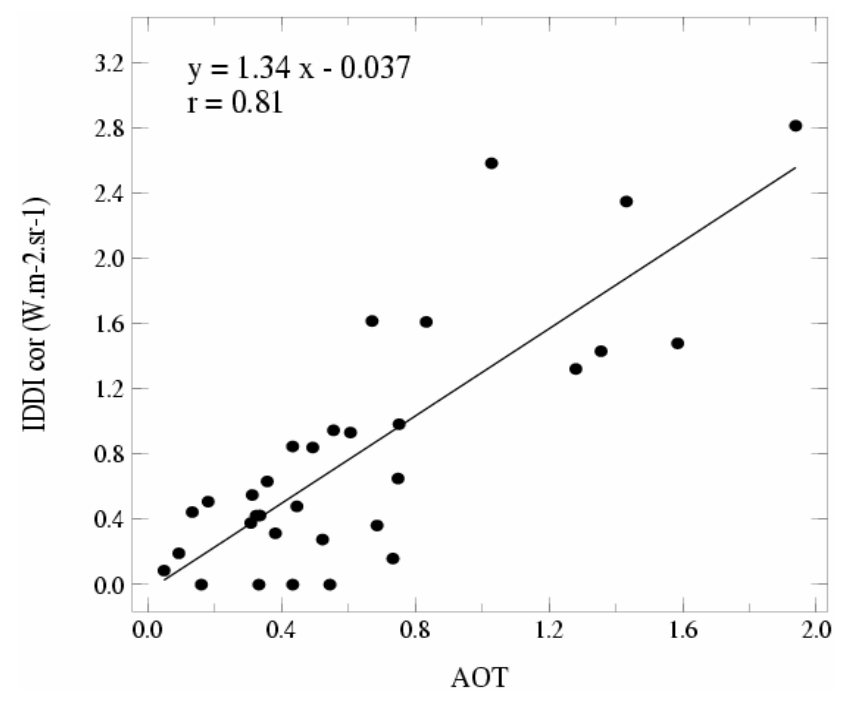

Fig. 10. Scatter plot of the IDDI corrected from the surface wind speed and the solar elevation effects versus the AOT at 12:00 UTC from 13 February to 31 March 1998, Banizoumbou.

revealed negligible. In conclusion, we obtain a parameterization of $T_{s}$ upon the solar zenith angle, the surface wind speed and the AOT, from which we can compute corrected TOA radiances using the MODTRAN radiative transfer code and then estimate corrected IDDI values. A significant improvement of the correlation coefficient from 0.63 to 0.86 is obtained comparing the AOT to the measured and the corrected radiances respectively. In addition, a difference from -1.10 to $+1.11 \mathrm{~W} \cdot \mathrm{m}^{-2} \cdot \mathrm{sr}^{-1}$ is observed between the two radiances. These results show that the three physical elements previously identified have a strong impact on the TOA radiances. So corrections of surface wind and solar elevation effects are applied to the TOA radiances and thus to the initial IDDI.

In this case study, the comparison between the corrected and the initial IDDI shows an increase of the correlation coefficient from 0.77 to 0.81 with the AOT and a decrease of the standard deviation from 0.85 to $0.75 \mathrm{~W} \cdot \mathrm{m}^{-2} \cdot \mathrm{sr}^{-1}$. The IDDI-AOT conversion factor is only weakly affected, from 1.41 to $1.34 \mathrm{~W} \cdot \mathrm{m}^{-2} \cdot \mathrm{sr}^{-1}$ per AOT unit increment (i.e. from 17.6 to 16.7 counts with the units used in the previous studies (Legrand et al. 2001)). So the applied corrections result in limited changes on the statistics even if it is obvious from the comparison of Figs. 1 and 9 that the day-to-day evolutions of IDDI and AOT are in much closer agreement (especially during the period from 22 February to 3 March).

But more importantly, the IDDI is shown to have a low sensitivity to variations of parameters such as the atmospheric water vapor or the aerosol optical properties. Hence reanalyses from forecast simulations (e.g. ECMWF) or climatological profiles as well as an approximate aerosol model could be used to perform the IDDI correction. This is 
particularly important in view of a systematic correction of METEOSAT and MSG imagery in the TIR. However, geographical limitations have to be considered. The IDDI is efficient in source areas and less in transport areas, so the correction is useful mostly for those latter areas. More investigations are however required to know whether the correction of the surface temperature obtained for the region of Niamey can be generalized to the Sahel and/or Sahara (outside the source regions) to process METEOSAT IR imagery during the dry season. In such a case, the radiance could be used as an alternative to the IDDI provided that the result showing that the corrected radiance is a better indicator of the AOT than the corrected IDDI, can be extended beyond the region of Niamey.

Acknowledgements. We are grateful to O. Boucher for the access to ECMWF data. We thank O. Pancrati for providing the photometric data and for his precious help in using the radiative transfer MODTRAN code.

Topical Editor F. D'Andrea thanks G. Bergametti and another referee for their help in evaluating this paper.

\section{References}

Anderson, G. P., Kneizys, F. X., Chetwynd, J. H., Wang, J., Hoke, M. L., Rothman, L. S., Kimball, L. M., McClatchey, R. A., Shettle, E. P., Clough, S. A., Gallery, W. O., Abreu, L. W., and Selby, J. E. A.: FASCODE/MODTRAN/LOWTRAN: Past/Present/Future, Proceedings of the Annual Conference on Atmospheric Transmission Models (18th), Massachusetts, 6-8 June, 1995.

Ben Mohamed, A. and Frangi, J.-P.: Results from Ground-based Monitoring of Spectral Aerosol Optical Thickness and Horizontal Extinction: Some specific Characteristics of Dusty Sahelian Atmospheres, J. Climate Appl. Meteor., 25, 1807-1815, 1986.

Brooks, N. and Legrand, M.: Dust variability over northern Africa and rainfall in the Sahel, in: Linking climate change to landsurface change, edited by: McLaren, S. J. and Kniveton, D., Kluwer Academic Publishers, 1-25, 2000.

Caquineau, S.: Les sources des aérosols sahariens transportés au dessus de l'atlantique tropical nord: localisation et caractéristiques minéralogiques, thesis, Université Denis Diderot Paris 7, France, 1997.

Caquineau, S., Gaudichet, A., Gomes, L., and Legrand, M.: Mineralogy of Saharan dust transported over northwestern tropical Atlantic Ocean in relation with sources regions, J. Geophys. Res., 107, doi:10.1029/2000JD000247, 2002.

D'Almeida, G. A.: A model for Saharan dust transport, J. Climate Appl. Meteor., 25, 903-916, 1986.

Dubovik, O., Holben, B., Eck, T. F., Smirnov, A., Kaufman, Y., King, M. D., Tanré, D., and Slutsker, I.: Variability of Absorption and Optical Properties of Key Aerosol Types Observed in Worldwide Locations, J. Atmos. Sci., 59, 590-608, 2002a.

Dubovik, O., Holben, B. N., Lapyonok, T., Sinyuk, A., Mishchenko, M. I., Yang, P., and Slutsker, I.: Non-spherical aerosol retrieval method employing light scattering by spheroids, Geophys. Res. Lett., 29, doi:10.1029/2001GL014506, 2002 b.
Herman, J. R., Bhartia, P. K., Torres, O., Hsu, C., Seftor, C., and Celarier, E.: Global distribution of UV-absorbing aerosols from Nimbus 7/TOMS data, J. Geophys. Res., 102, 16911-16922, 1997.

Hsu, N. C., Tsay, S.-C., King, M. D., and Herman, J. R.: Aerosol properties over bright-reflecting source regions, IEEE Trans. Geosci. Remote Sensing, 42, 557-569, 2004.

Kahn, R. A., Gaitley, B. J., Martonchik, J. V., Diner, D. J., Crean, K. A., and Holben, B.: Multiangle Imaging Spectroradiometer (MISR) global aerosol optical depth validation based on 2 years of coincident Aerosol Robotic Network (AERONET) observations, J. Geophys. Res., 110, D10S04, doi:10.1029/2004JD004706, 2005.

Legrand, M., Cautenet, G., and Buriez, J.-C.: Thermal Impact of Saharan Dust over Land. Part II: Application to Satellite IR Remote Sensing, J. Appl. Meteorol., 31, 181-193, 1992.

Legrand, M., Plana-Fattori, A., and N'Doumé, C.: Satellite detection of dust using the IR imagery of Meteosat 1. Infrared difference dust index, J. Geophys. Res., 106, 18 251-18 274, 2001.

Léon, J.-F. and Legrand, M.: Mineral dust sources in the surroundings of the north Indian Ocean, Geophys. Res. Lett., 30, 1309, doi:10.1029/2002GL016690, 2003.

Liao, H. and Seinfeld, J. H.: Radiative forcing by mineral dust aerosols: sensitivity to key variables, J. Geophys. Res., 103, $31637-31645,1998$.

Marticorena, B., Bergametti, G., Aumont, B., Callot, Y., N'Doumé, C., and Legrand, M.: Modeling the atmospheric dust cycle: 2. Simulation of Saharan dust sources, J. Geophys. Res., 102, 4387-4404, 1997.

Marticorena, B., Chazette, P., Bergametti, G., Dulac, F., and Legrand, M.: Mapping the aerodynamic roughness length of desert surfaces from the POLDER/ADEOS bi-directional reflectance product, Int. J. Remote Sensing, 25, 603-626, 2004.

Moulin, C., Lambert, C. E., Dayan, U., Masson, V., Ramonet, M., Bousquet, P., Legrand, M., Balkanski, Y. J., Guelle, W., Marticorena, B., Bergametti, G., and Dulac, F.: Satellite climatology of African dust transport in the Mediterranean atmosphere, J. Geophys. Res., 103, 13 137-13 144, 1998.

Pancrati, O.: Télédétection de l'aérosol désertique depuis le sol par radiométrie infrarouge thermique multibande, thesis, Université des Sciences et Technologies de Lille, France, 2003.

Petit, R.-H., Legrand, M., Jankowiak, I., Molinié, J., Mansot, J.-L., Marion, G., and Asselin de Beauville, C.: Transport of Saharan dust over the Caribbean Islands. Study of an event, J. Geophys. Res., 110, D18S09, doi:10.1029/2004JD004748, 2005.

Pierangelo, C.: Apports du sondage infrarouge à l'étude des aérosols atmosphériques. Application aux instruments HIRS et AIRS : Caractérisation des aérosols en épaisseur optique, en altitude et en taille, thesis, Université Pierre et Marie Curie - Paris 6, France, 2005.

Prospero, J. M. and Lamb, P. J.: African droughts and dust transport to the Caribbean: climate change implications, Science, 302, 1024-1027, 2003.

Seinfeld, J. H., Carmichael, G. R., Arimoto, R., Conant, W. C., Brechtel, F. J., Bates, T. S., Cahill, T. A., Clarke, A. D., Doherty, S. J., Flatau, P. J., Huebert, B. J., Kim, J., Markowicz, K. M., Quinn, P. K., Russell, L. M., Russell, P. B., Shimizu, A., Shinozuka, Y., Song, C. H., Tang, Y., Uno, I., Vogelmann, A. M., Weber, R. J., Woo, J.-H., and Zhang, X. Y.: ACE-ASIA: 
Regional Climatic and Atmospheric Chemical Effects of Asian Dust and Pollution, Bull. Amer. Meteorol. Soc., 85, 367-380, 2004.

Sokolik, I., Toon, O. B., and Bergstrom, R. W.: Modeling the radiative characteristics of airborne mineral aerosols at infrared wavelengths, J. Geophys. Res., 103, 8813-8826, 1998.
Tanré, D. and Legrand, M.: On the Satellite Retrieval of Saharan Dust Optical Thickness Over Land: Two Different Approaches, J. Geophys. Res., 96, 5221-5227, 1991.

Tanré, D., Kaufman, Y. J., and Holben, B. N.: Climatology of dust aerosol size distribution and optical properties derived from remotely sensed data in the solar spectrum, J. Geophys. Res., 106, 18 205-18 217, 2001. 